\title{
Doctoral and Masters Supervision: The Potential Role of Self-Efficacy
}

\author{
Chris William Callaghan \\ School of Economic and Business Sciences \\ University of the Witwatersrand \\ E-mail: chris.callaghan@wits.ac.za
}

\section{Doi:10.5901/mjss.2014.v5n3p404}

\begin{abstract}
This research investigated the potential contribution of self-efficacy and different forms of experience to the numbers of sucessful doctoral and masters degree supervisions of academics. Using a comprehensive purposive sampling procedure, academics at a large South African higher educational institution were sampled; 225 responses were received. Spearman Rho tests of association, Pearson partial correlation analysis, and hierarchical regression analysis were used to test the relationships between different types of self-efficacy, together with different forms of experience, and measures of doctoral and masters degree supervisions. Findings suggest that self-efficacy accounts for variance in doctoral and masters degree supervisions over and above the contribution of years of experience as a researcher, job satisfaction, gender and the number of people reporting to an individual. However, the effect of self-efficacy might only be significant up and until the point that an individual gains sufficient supervisory experience, of one form or the other (doctoral or masters degree supervision). Male academics are found to supervise more doctoral students. Individuals that supervise more doctoral students are found to have significantly higher levels of self-efficacy relating to statistical analysis.
\end{abstract}

Keywords: tertiary education; research output; self-efficacy; job performance; postgraduate supervision;

\section{Introduction}

The South African system of higher education exists in a resource-constrained context (ASAf, 2010); yet is at the heart of a developing nation's attempts to meet the needs of its people (Brown and Czerniewicz, 2010).

It is the individual academic, however, that needs to produce research, to contribute to the needs of societal stakeholders; research is a work task. For Bandura (1982:122), the dominant determinant of success in work tasks is primarily related to an underlying psychological mechanism associated with an individual's self-efficacy, or a personal interpretation of "how well one can execute courses of action required to deal with prospective situations".

Self-efficacy is currently being researched extensively in the educational context. For example, self-efficacy has recently been studied in relation to language education (Locke, Whitehead and Dix, 2013), pre-service teacher learning (Bernadowski, Perry and Del Greco, 2013; Briley, 2012), instructional leadership (Calik, Sezgin, Kavgaci, 2012), schoollevel environments (Ghasemizad, Khajehei and Mohamadkhani, 2013); and a host of other areas.

Much literature also exists; that suggests associations and relationships around doctoral and masters degree supervision in the South African context (for example, see Albertyn, Kapp and Bitzer, 2008; Mouton, 2007; Waghid, 2011).

Despite these bodies of literature, however, the literature in the contemporary South African context provides little evidence of the relationships between different dimensions of self-efficacy and doctoral and masters degree supervision. The purpose of this study is to address this deficiency in the literature.

The problem addressed in this paper is therefore the lack of knowledge as to what extent different dimensions of self-efficacy are related to higher numbers of successful doctoral and masters student supervisions by individual academics. The research question posed in this research is therefore the following: To what extent are different dimensions of self-efficacy related to more successful postgraduate supervisions? The relative contributions to supervisions by self-efficacy related to (i) Thompson Reuters Institute for Scientific Information (ISI) or ProQuest International Bibliography of the Social Sciences (IBSS) indexed, or accredited, journal article publication, (ii) South African Department of Higher Education accredited journal article publication, (iii) conference proceedings publication, (iv) conference presentation, (v) statistical analysis, (vi) qualitative analysis, and (vii) total research self-efficacy, which is a measure comprising (i), (ii), (iii) and (iv) that reflects self-efficacy associated with all these forms of research output. On 
the basis of the analysis, a typology of self-efficacy dimensions and their relative relationships with numbers of successful doctoral and masters supervisions is presented.

The contribution this article makes is threefold. Firstly, from a theoretical perspective, the study offers insight into the boundary conditions and contextual contingencies that operate around the predictions of self-efficacy theory in this context; as they relate specifically to postgraduate supervision.

Secondly, from a practical perspective, this study provides empirical evidence that may be helpful to academics in their attempts to increase the effectiveness of their supervision of doctoral and masters students.

Thirdly, this study extends global, or international, theory and research findings into the South African context for testing; while implications for practice can already be derived from the global literature, such a process might impose a cost on stakeholders if this theory and these findings do not generalise into this context.

Data from a large South African university is therefore used to test the predictions of self-efficacy theory. It is argued that the generalisability of international literature cannot be assumed, given that the South African higher education context may differ from other global contexts.

What has also been underexplored is the extent to which certain effects and associations are similar across different fields of a university. This research offers a test of self-efficacy relationships that are robust to the differences that exist across academic fields; in other words, that are generalisable across different academic fields, and to other South African higher education contexts, to the extent that these share characteristics with the one under study.

The South African context of doctoral and masters degree supervision is now introduced, in order to contextualise the study. This is followed by a discussion of the study's theoretical framework, where hypotheses are derived. Subsequently, the methodology and research design of the study are considered. The results are then presented and discussed. Implications for practice are derived. The paper is then concluded following a discussion of suggestions for further research.

\section{Literature Review}

Literature relating to postgraduate supervision and self-efficacy is now introduced.

\subsection{The South African context of higher education}

The South African context of higher education differs from other global contexts in certain ways; certain differences that have implications for this study stand out. Only approximately a third of permanent academic staff at South African higher education institutions have doctorates (ASAf, 2010).

The approximate ratio of doctoral students to academic staff that can supervise doctorates is 2:1 (ASAf, 2010). A primary issue relating to doctoral supervision in South Africa is therefore the shortage of staff with doctorates at South African universities.

In 2007, South Africa produced 1274 doctoral graduates, representing 26 graduates per million of its population (ASAf, 2010). This contrasts, for example, with 251 per million for Australia, 201 for the United States, 288 for the United Kingdom and 297 for Germany (ASAf, 2010). Doctoral production is not equal amongst South African universities.

In 2007, the top nine higher education institutions in the country were found to account for $83 \%$ of these doctoral graduates (ASAf, 2010). These were, in order of production from highest to lowest; the Universities of Pretoria, Stellenbosch, Cape Town, Witwatersrand, North-West, KwaZulu-Natal, UNISA, Free State and Johannesburg (ASAf, 2010).

The effectiveness of supervision, given this shortage of doctoral supervisors, is therefore critically important in this context; if these relatively few supervisors could be empowered to be more effective in their supervision then more students could be supervised.

\subsection{The importance of doctoral (and masters) degree supervision}

The production of doctoral graduates is important for many reasons. South Africa's production of doctorates has benefits for the country. There is a "strong relationship between the production of doctoral graduates and economic growth"; as frontier research is increasingly important in knowledge-based economies (ASAf, 2010:116). This view is "grounded in endogenous growth theory (or new growth theory); which contends that the enhancement of a nation's human capital will lead to economic growth by means of the development of new forms of technology and efficient and effective means of 
production" (ASAf, 2010:116).

Doctoral education "prepares researchers with the skills to be innovative, creative, critical and independent; these skills are not only related to the research process itself, but to a broader personal and professional training and development, thus providing highly talented human resources that are necessary for such growth" (ASAf, 2010:116).

The purpose of a doctorate, according to academics that run doctoral programmes, is to provide: (i) training for an academic career; (ii) training for industry; and (iii) training for a profession (ASAf, 2010). "As a core function of universities, doctoral research provides invaluable education and training aimed at producing highly skilled knowledge workers capable of transferring their intellectual and technical expertise to wide-ranging global contexts" (ASSAf, 2010:35). Masters degree supervision is also taken to contribute directly to these outcomes, as a masters degree typically provides the foundation for doctoral studies, and is a usually a pre-requisite to doctoral studies.

\subsection{Theory and previous empirical findings relating to South African postgraduate supervision in general}

The rate at which doctoral graduates are produced is indicative of the sustainability of a knowledge system and is related to the ability of a knowledge system to reproduce itself (ASAf, 2010).

A shortage of doctoral supervisors, together with high supervisor-student ratios, indicates that a crisis in advisory capacity is faced by South African universities (ASAf, 2010). This problem is exacerbated by an aging professoriate (ASAf, 2010).

In South Africa, five models of doctoral training dominate: (i) the apprenticeship model, which consists primarily of individual mentoring, but can be supplemented by support programmes; (ii) the course work model, which includes an apprenticeship; (iii) the cohort-based model which is based on groups of students and supervisors; which is targeted at providing economies of scale; and (iv) the doctorate that is awarded through publications (ASAf, 2010).

The apprenticeship model is dominant in the country (ASAf, 2010). Doctoral studies are also highly contextspecific and differences between disciplines and universities make standardisation of doctoral training challenging (ASAf, 2010). The role of the individual supervisor in this process is therefore particularly important.

The characteristics of these supervisors that might be related to successful postgraduate supervision are therefore considered to be particularly important. It is in this context, therefore, that Bandura's (1982:122) argument; that selfefficacy can be the dominant determinant of success in certain work tasks is tested, as a characteristic of individual academics that might be associated with postgraduate supervision as a work task.

At this point, it is necessary to discuss why a shortage in postgraduate doctoral supervisors exists in the South African higher education system; in case the reason for this also influences the relationships between self-efficacy and postgraduate supervision in this context.

Why then, does South Africa have so few doctoral graduates; and, hence, so few doctoral supervisors? In the South African context, "[i]ndisputably, constraints on doctoral production lie deep within the school system, where only $16 \%$ of graduating matriculants qualify for university entrance (the exemption pass)" (ASAf, 2010:107).

According to the literature, a "vast range" of problem areas have been found to relate to postgraduate supervision (Aspland, Edwards, O'Leary and Ryan, 1999).

Literature indicates that low completion and high attrition rates are the primary problem with South African doctoral production, according to Mouton (2007). Mouton (2007), however, disagrees with this body of literature. Mouton (2007) argues that while the number of academics has increased by less than $20 \%$, over the same period an increase of over $300 \%$ has occurred in masters and doctoral enrolments. Further, over this period academic research output increased from 5000 to 6600 units of output (Mouton, 2007).

For Mouton (2007), the following are more pressing problems than low completion or high attrition rates: (i) overburdened and inexperienced supervisors; (ii) a lack of research preparation for doctoral candidates; (iii) a lack of national and institutional financial support for students, and (iv) a lack of institutional attention and resources for postgraduate support. Masters degree supervision is therefore also a part of the process.

Although this body of literature relates to doctoral training, relatively less literature is devoted to masters degree training. This research attempts to also focus on certain differences between doctoral and masters degree supervision. Literature that relates to both forms of supervision, or to postgraduate supervision in general, is therefore now also considered.

Typically, the postgraduate supervision literature has been concerned with "supervisory orientations and strategies, ways to handle postgraduate students, challenging postgraduate education practices, factors related to success in postgraduate studies, the benefits of advanced studies, transition to independent research and researcher 
identity development" (Bitzer 2011:855).

However, what is common to all forms of postgraduate supervision is the ability to develop critical thinking skills in students. Postgraduate supervision "ought to be an encounter framed by skepicism" (Waghid; 2011:393).

Over and above the need for critical thinking, postgraduate supervision needs to also take into account changes over time. Transitions in the modes of learning, from traditional forms toward learning that needs to address the complexity of the knowledge economy, have also necessitated changes in the training of postgraduate students (Albertyn, Kapp and Bitzer, 2008).

However, a tension also typically exists; between the demands of students, including time-related demands, and the ability of supervisors to provide the necessary time investments in the process (Singh, 2011).

Supervisors also typically complain of the poor quality of students and the failure of prior qualifications to prepare students for postgraduate studies (Singh, 2011). The failure of students to apply suggestions and corrections and the time taken to edit dissertations and theses are also common complaints of supervisors, particularly as many students in South African institutions are not first language English speakers (Singh, 2011). Dissatisfaction with the supervision process can also lead to higher attrition rates amongst postgraduate students (Aspland et al., 1999).

Albertyn et al. (2008:761) found that students regarded certain characteristics as important strengths in a supervisor; these include "guidance, support, expertise, professionalism, personal attributes and timeous feedback". Similarly, students in general were found to indicate certain areas in which improvement was needed; these include "greater involvement in preparing the student for research methods and design; training in writing for publication from a thesis; technical support for example where to find information; keeping track of the progress of students; and quicker feedback" (Albertyn et al., 2008:761).

For Fraser and Mathews (1999), there are different phases in a research project, which require different types of support; (i) 'the settling in and getting going' phase, which requires a supervisor to ensure that the student feels capable to complete; a supervisor needs to provide enthusiasm and involvement during the process; (ii) 'maintaining the impetus', where students need to be reassured and shown the big picture of what they have done and what they are yet to achieve; (iii) 'finishing off', where students have to face criticism and to rework their research when intellectually exhausted; at this stage a supervisor should encourage rearranging and rebuilding rather than breaking it down.

From the above discussion, it is clear that the individual characteristics of supervisors are an important dimension of study. However, although there might be characteristics of supervisors that are related to successful postgraduate supervision, the issue remains: would Bandura's (1982) predictions; that self-efficacy is a dominant influence on task performance, generalise across different disciplines, given that substantive differences exist between academic fields?

\subsection{Postgraduate supervision and disciplinary differences between academic fields}

Much of the literature that relates to postgraduate supervision seems to be discipline-specific. Postgraduate supervision, itself, is not uniform across academic fields (Bitzer 2011). Potential disciplinary differences in supervision are therefore important considerations. In order to convey a sense of what differences can exist between supervision across different fields, an example from the South African context follows.

Winberg (2009) found disciplinary differences in co-supervision relationships between engineering and education. These "revealed themselves in different ways as the research projects progressed- from establishing a research focus, to developing appropriate methodologies, presenting and analysing the research findings" (Winberg, 2009:208). Further, such differences extended to disciplinary norms for what was considered valid knowledge, and what should be the focus of research topics (Winberg, 2009).

Engineering supervisors held implicit assumptions that "knowledge building in engineering is about the accumulation of facts" (Winberg, 2009). In contrast, educators "tended to adopt the post-modern position that facts are fluid and elusive, so that we should focus on observational claims, rather than assumed 'facts'" (Winberg, 2009:209). However, supervisors from both fields drew on the "stability, continuity and order" provided by their disciplines, which informed their assumptions relating to supervision (Winberg, 2009:209). For Winberg (2009), this is akin to Giddens's (1984) state of 'ontological security'.

The use of this example highlights differences in supervision relationships between academic fields; differences in supervision are to be expected as the norm across other fields too (Winberg, 2009). Differences also exist in the numbers of doctoral students produced by different fields (ASAf, 2010).

Doctoral graduates in education, economic and management sciences and religious studies dominate (ASAf, 2010). Social sciences doctoral output is five times higher than in the fields of engineering sciences, materials and 
technologies (ASAf, 2010).

In a perhaps relatively heterogeneous context of postgraduate supervision, it is argued that this research offers insights that exist over and above the influence of differences between fields; because it involves the testing of relationships that are robust enough to these differences.

Having fore-grounded the importance of disciplinary differences in supervision and differences in postgraduate supervision that might be context-related, the focus of the review of the literature now shifts to self-efficacy.

\title{
2.5 Self-efficacy and Postgraduate Supervision
}

For Bandura (1977), self-efficacy can be the dominant influence on an individual's ability to successfully perform a task. It is therefore accorded a central place in the investigation of postgraduate supervision in this context, framed as a work task.

Self-efficacy represents a personal interpretation of "how well one can execute courses of action required to deal with prospective situations" (Bandura, 1982:122).

Historically, the workplace literature has found support for Bandura's (1982) predictions; that self-efficacy is positively associated with job performance. Meta-analysis findings support a positive relationship between self-efficacy and job performance (Stajkovic and Luthans, 1998). However, self-efficacy is more weakly associated with work-related performance when the tasks involved are higher in complexity (Stajkovic and Luthans, 1998). Postgraduate supervision might be a task high in complexity, so it is not clear the extent to which self-efficacy might be related to higher numbers of supervisions.

For Bandura (2006:309), self-efficacy beliefs, however, also influence "whether people think erratically or strategically, optimistically or pessimistically" and also:

\begin{abstract}
influence the course of action people choose to pursue, the challenges and goals they set for themselves and their commitment to them, how much they put forth in given endeavours, the outcomes they expect their endeavours to produce, how long they persevere in the face of obstacles, their resilience to adversity, the quality of their emotional life and how much stress and depression they experience in coping with taxing environmental demands, and the life choices they make and the accomplishments they realise.
\end{abstract}

The causal mechanisms along which self-efficacy can work to facilitate higher levels of postgraduate supervision success might therefore also be related to the effort an individual puts into, and their perseverance in this form of task (Bandura, 2006).

A deeper investigation of the derivation of this causal model is considered beyond the scope of this paper because its focus is delimited to the testing of empirical associations between self-efficacy and postgraduate supervision as a form of job or work performance.

Bandura (1977:191) argues that self-efficacy, as a construct, can offer a unifying theory of behavioural change, because it is related to a "common cognitive mechanism". Although cognitive processes can mediate change in behaviour, "cognitive events are induced and altered most readily by experience of mastery arising from effective performance" (Bandura, 1977:191).

The "initial approximations of response patterns learned observationally are further refined through self-corrective adjustments based on informative feedback from performance" (Bandura, 1977:192). The reinterpretation of contingent effects as predictive cues "has shifted the locus of the regulation of behaviour from the stimulus to the individual" (Bandura, 1977:192). Further, because beliefs about the consequences of outcomes, or reinforcement, can have a stronger influence on behaviour than the reinforcement stimulus itself, self-efficacy can directly influence performance on tasks (Bandura, 1977:192). For Bandura (1977:193):

\footnotetext{
Self-motivation involves standards against which to evaluate performance. By making self-rewarding reactions conditional on attaining a certain level of behaviour, individuals create self-inducements to persist in their efforts until their performances match self-prescribed standards. Perceived negative discrepancies between performance and standards create dissatisfactions that motivate corrective changes in behaviour. Both the anticipated satisfactions of desired accomplishments and the negative appraisals of insufficient performance thus provide incentives for action. Having accomplished a given level of performance, individuals often are no longer satisfied with it and make further self-reward contingent on higher attainments.
}

A focus on self-efficacy reflects a reconceptualisation "of human learning and motivation in terms of cognitive 
processes", that offers a dominant causal mechanism for learning and motivation related to the performance of tasks (Bandura, 1977:193).

To the extent that research work shares certain commonalities with postgraduate supervision of research, selfefficacy relating to a host of research-related outcomes is expected to be associated with more effective or efficient research degree supervisions. On the basis of the above discussion, Hypothesis a and b are derived: Hypothesis $a$, that there is a significant association between research-related self-efficacy and the number of doctoral students an academic has supervised; and Hypothesis b, that there is a significant association between research-related self-efficacy and the number of masters students an academic has supervised.

According to an analysis of the job performance literature, certain other variables seem to be prominent in previous research. In order to not confound the investigation of the relationships between self-efficacy and postgraduate supervisions, certain of these variables are included as covariates. These variables are now considered as follows.

According to human capital theory (Becker, 1964), investments in learning and experience are predicted to contribute to productivity. Years of experience are therefore expected to contribute to accumulated learning, and are therefore expected to be positively related to numbers of successful doctoral and masters supervisions.

Job satisfaction is a dominant variable in the job performance literature in that it captures net performance-related effects associated with an individual's intrinsic engagement with a job (Callaghan, 2012). Job satisfaction is the "pleasurable emotional state resulting from the appraisal of one's job as achieving or facilitating one's job values" (Locke, 1969:317).

Satisfaction is predicted to be related to performance because dissatisfaction has been found to be associated with the withdrawal of intrinsic engagement in tasks (Organ, 1988). Certain meta-analysis findings support the positive relationship between job performance and job satisfaction (Judge, Thorensen, Bono \& Patton, 2001). The type of work tasks involved, however, also influence an individual's motivation and job performance in tasks (Hackman \& Oldham, 1976; Herzberg, 1968).

In order to be able to test the relationships between self-efficacy and postgraduate supervision 'net' of the influence of job satisfaction and experience, these covariate factors were included in a multivariate analysis.

\section{Research Methodology}

\subsection{Participants}

The study applied an exploratory cross-sectional associative research design. The sampling frame of the study consisted of all staff at a large South African higher education institution; consisting of about 1300 full time and part-time staff (response rate about 17\%). The entire institution was sampled. Respondents were invited to respond by returning completed questionnaires through the internal mail system using self-addressed envelopes; 225 usable responses were received. Refusals were unconditionally respected, on ethical grounds.

About $47 \%$ of the sample were male (Table 1), reflecting the numerial dominance of females in employment in this context. The mean age of the academics sampled is 40.67 years. Mean experience is 14.6 years of total working experience, 10.2 years of experience as a researcher, and 6.39 years of experience working for the institution. On average, an academic is found to have supervised just over six masters students and just under one doctoral student over the course of his or her career. However, given the skewness associated with postgraduate supervision, it seems that a relatively small number of academics contribute most of the output in postgraduate supervisions.

\subsection{Scales, Measures and Data Analysis}

Bivariate tests were used to thest the relationships between self-efficacy and masters and doctoral supervisions. A multivariate analysis was also undertaken; the factors that predict masters and doctoral supervision net of experience and satisfaction effects were also tested. Hierarchical multiple linear regression analysis was applied. The contribution of self-efficacy to doctoral and masters supervision net of the influence of the covariate factors was tested.

On the basis of theory, covariate variables were included in the multiple linear regression models. Job satisfaction was measured using seven-point Likert-type scales, derived from the Minnesota Satisfaction Questionnaire scales (Arvey, Bouchard, Segal \& Abraham, 1989). Three items were used to measure Job Satisfaction. The items were reversed each time. The Cronbach Alpha obtained for these items was 859.

The self-efficacy items were derived from Bandura's (2006) scales, and designed to capture the theoretical domain 
relevant to each research-related self-efficacy item in this context. Graduations, or levels, of challenge were incorporated into the scale design. The adapted items were developed to specifically relate to each of the following self-efficacy dimensions: self-efficacy relating to (i) ISI/IBSS accredited/indexted journal article publication, (ii) DOHET journal article publication, (iii) conference proceedings publication, (iv) conference presentations, (v) postgraduate teaching selfefficacy, (vi) statistical analysis self-Efficacy and (vii) qualitative analysis self-efficacy. The items were piloted before use in the final instrument. Across the sample, the Cronbach's Alpha value for all of the seven self-efficacy items was .783.

\section{Findings and Discussion}

The results of the study are reported as follows, under the relevant hypotheses, which are used as headings. Other significant associations are also discussed under these headings.

\subsection{Hypothesis a: There is a significant association between research-related self-efficacy and the number of doctoral students an academic has supervised.}

Individuals who have supervised more doctoral students are found to have significantly higher levels of self-efficacy related to publication of ISI/IBSS journal articles $(.344 ; p<.0001)$, DOHET journal articles $(.358 ; p<.001)$, conference proceedings publications $(.286 ; p<.0001)$, conference presentations $(.226 ; p<.001)$, statistical analysis $(.164 ; p<.014)$ and to total research output $(.336 ; p<.0001)$.

In all cases the Spearman Rho tests were subjected to bootstrapping and the confidence intervals were checked to ensure that they supported the tests of significance.

According to Bandura (2006), higher levels of self-efficacy can enable an individual to think optimistically and strategically rather than pessimistically or erratically. Further, self-efficacy can influence an individual's perseverance in tasks and goal attainment (Bandura, 2006). These results are consistent with Bandura's (2006) predictions; that selfefficacy in a related task (research production) can make a dominant contribution to performance in a task (postgraduate research supervision).

However, the directionality of the relationship is not clear from these findings; it might be possible that higher levels of self-efficacy in these two specific areas of research output (ISI/IBSS journal articles or DOHET journal articles) do 'cause' doctoral supervision but it is also possible that the causal direction can flow the other way. The relationship might also be fundamentally non-recursive; the causal effects might flow both ways.

According to Bandura's (2006) theory, however, it is entirely possible that self-efficacy relating to these different activities might reinforce each other; a virtuous circle of self-efficacy can develop. This potentiality is possibly evident in the associations found between research outputs and doctoral supervisions.

The challenge for practice would therefore be how to create this virtuous circle in an individual's research, following Bandura's (2006) perspective.

According to the Spearman Rho tests, doctoral supervisions are positively associated with the following measures of research experience: ISI/IBSS accredited journal articles $(.523 ; p<.0001)$, DOHET accredited journal articles $(.392 ; p<.0001)$, conference proceedings publications $(.356 ; p<.0001)$, conference presentations $(.419 ; p<.0001)$, book publications $(.405 ; p<.0001)$, book chapters $(.466 ; p<.0001)$ and total units of output $(.542 ; p<.0001)$.

The strongest effect seems to be that related to internationally accredited journal article publication, followed by conference presentations and then book publications. A question arises here; what is the association between selfefficacy and doctoral supervisions net of, or over and above, the contributions of experience in the form of previous research output? In other words, is it possible that self-efficacy contributes to postgraduate supervision over and above the influence of research experience?

For the purposes of further analysis, Pearson partial correlation tests were undertaken. With total units of research output controlled, total research self-efficacy is found to be significantly associated with numbers of doctoral students supervised $(.147 ; \mathrm{p}<.028 ; \mathrm{Cl}=.034(\mathrm{l}) ; .232(\mathrm{u}))$.

According to these results, it is argued that self-efficacy is associated with doctoral supervisions over and above the influence of the research output-related experience. These results are consistent with Bandura's (2006) predictions; that self-efficacy is a dominant factor in facilitating the success of certain work task performance.

The significant association between doctoral supervisions and statistical analysis self-efficacy suggests that it might be possible that an individual's confidence in statistical methods may contribute to an individual's success in supervising doctorates. 
Further analysis was applied, in order to understand whether these relationships were independent of years of experience as a researcher, which according to Becker's (1964) human capital theory was expected to be the primary covariate.

When the influence of years of experience as a researcher was controlled for using partial correlation analysis, doctoral supervision remained positively and significantly associated with (i) total research self-efficacy $(.195 ; p<.003$; $\mathrm{Cl}=.00(\mathrm{l}) ; .305(\mathrm{~h})$; (ii) ISI/IBSS journal publication self-efficacy $(.145 ; \mathrm{p}<.03 ; \mathrm{Cl}=.038(\mathrm{l}) ; 232(\mathrm{~h})$ and statistical analysis selfefficacy $(.227 ; \mathrm{p}<.001 ; \mathrm{Cl}=.106(\mathrm{l}) ; .334(\mathrm{~h}))$.

These results suggest that total research self-efficacy might contribute to doctoral supervision over and above the influence of years of experience as a researcher as well as the influence of total research outputs. However, it is acknowledged that this is not causal research; correlations cannot ascribe causality, and cannot ascribe the directionality of causal relationships. However, these results do support Bandura's (2006) theoretical predictions- that self-efficacy will cause higher levels of success in work tasks, in this case the work task of postgraduate supervision; net of the influence of experience itself.

Drawing on Bandura's (2006) theory, the provision of statistical training for potential doctoral supervisors might empower these individuals to be more productive as doctoral supervisors. A lack of confidence in one's statistical ability might be a dominant constraint to doctoral supervision; a proactive approach by Schools to empower their staff with statistical training might improve doctoral supervision rates.

At this point of the testing process, the question remained; was the potential influence of total research selfefficacy on doctoral supervision in evidence over and above the influence of masters degree supervision? This association is significant when masters supervisions (.177; $\mathrm{p}<.008 ; \mathrm{Cl}=.079(\mathrm{l}) ; .291(\mathrm{~h}))$ and when both masters degree supervisions and years of experience as a researcher $(.148 ; p<.028 ; \mathrm{Cl}=.046(\mathrm{l}) ; .265(\mathrm{~h}))$ are included as control variables in the partial correlation process.

Similarly, when years as a researcher and masters degree supervision are controlled for, the association between statistical analysis self-efficacy and doctoral supervision is again found to be significant $(.244 ; \mathrm{p}<.0001 ; \mathrm{Cl}=.05(\mathrm{l}) ; .346(\mathrm{~h}))$. Statistical analysis self-efficacy seems to be a key difference between individuals that supervise large numbers of doctoral students versus masters students. In order to contextualise these relationships, associations of doctoral supervision with the range of other contextual factors tested are discussed as follows.

Gender differences are also found. According to t-test results (bootstrapped), unlike in the case of masters supervisions, males are found to be significantly more likely to have supervised more doctoral students (mean difference=1.109;p<.016; $\mathrm{Cl}=.473(l) ; 1.804(h))$.

The Pearson correlation coefficient for the association between masters supervision and doctoral supervision is $.531(\mathrm{p}<.0001 ; \mathrm{Cl}=.388(\mathrm{l}) ; .689(\mathrm{~h}))$. The coefficient of determination is therefore .282, which indicates that these variables share just over a quarter of their variance. This suggests that individuals that successfully supervise significantly higher numbers of doctoral students are also more likely to supervise higher numbers of masters degree students. This result, however, also suggests that $71.8 \%$ of the variance in doctoral supervision is not explained by masters degree supervision; these two forms of supervision might therefore differ along substantive dimensions.

According to the Spearman tests, individuals that supervise more doctoral students have significantly more people reporting to them $(.261 \mathrm{p}<.0001 ; \mathrm{Cl}=.118(\mathrm{l}) ; .409(\mathrm{~h}))$, yet not when years as a researcher were controlled. However, when years as a researcher are controlled, this association is found to no longer be significant $(.130 ; \mathrm{p}<.052 ; \mathrm{Cl}=-.075(\mathrm{l})$; $.294(h)$ ). Academics in management roles might not necessarily supervise more, or less, than others. Indeed, these results suggest that having a management role in this context might not be a constraint to postgraduate supervision.

Doctoral supervision is negatively associated with satisfaction with teaching $(-.171 ; p<.01)$ yet positively associated with satisfaction with research $(.149 ; p<.026)$. This suggests a potential tension between doctoral supervision and teaching as a specific locus of satisfaction. Further research should investigate this further; workload models should perhaps differentiate between these activities to support comparative advantage between individuals based on their intrinsic satisfaction preferences. These latter associations are, however, not present for masters degree supervisions.

Doctoral supervisions are, however, also positively associated with self-efficacy related to postgraduate teaching $(.372 ; p<.0001)$, as in the case of masters supervisions. This suggests that individuals who supervise more doctoral students might be more confident in their ability to teach at the postgraduate level. There might be a synergy between teaching at this level and postgraduate supervison.

Doctoral supervisions are also associated with other countries lived in for a period of over a year $(.296, p<.0001)$, total years of work experience $(.405 ; p<.0001)$, years as a researcher $(.524 ; p<.0001)$, years working for the institution $(.408 ; p<.0001)$, membership of professional associations $(.237 ; p<.0001)$ and years of formal education $(.170 ; p<.015)$. 
These were, however, bivariate relationships, and multivariate testing was also applied in order to understand the potential contribution of self-efficacy to postgraduate supervision over and above the influence of these human capital influences (Becker, 1975).

Years as a researcher was the dominant human capital variable according to these tests; in order to control for multicollinearity and singularity in the multivariate testing this variable was included on its own to represent these effects.

In order to gain insight into the multivariate relationships around self-efficacy in this context, hierarchical linear regression analysis was used. In each case, the control variables were first included, and then total research self-efficacy was entered into the equation. This made it possible to determine how much variance in each form of postgraduate supervision (masters and doctoral supervision) was explained by the self-efficacy variable. Total research self-efficacy, or research self-efficacy, was found to explain $1.9 \%$ of the variance in doctoral supervisions over and above the influence of the covariates.

A further test was run to determine the amount of variance in doctoral supervision explained by masters degree supervision, over and above the influence of research self-efficacy and the other covariate factors. As discussed in the methodology section, job satisfaction, years as a researcher, people reporting to an individual and gender were included as covariates. The model explains $20.7 \%$ of the variance in doctoral supervisions. However, the addition of masters degree supervisions to the model is found to explain $16 \%$ of the variance in doctoral supervisions over and above the influence of the covariates in the model.

With masters degree supervision included in the model, over a third of the variance in doctoral supervision is explained; years as a researcher are no longer significant. This suggests that experience in masters degree supervision dominates the model. When masters degree supervision is included in the model, research self-efficacy is also no longer significant.

This model was run again with each of the subordinate self-efficacy variables (self-efficacy relating to ISI/IBSS journal article publication, DOHET journal article publication conference proceedings publication, conference presentations, statistical analysis and qualitative analysis). Only the model including self-efficacy related to statistical analysis was found to be significant $(p<.021 ; \beta=.013(.158) / C l=.005(\mathrm{l}) ; \mathrm{Cl}=.022(\mathrm{u}))$. This model has an $\mathrm{R}$ squared value of .374 and an adjusted $R$ squared value of .357 .

This model, through its inclusion of masters degree supervision together with statistical analysis self-efficacy, explains the most variance in doctoral supervision (16.9\%) over and above the influence of the covariates. In this model, gender $(p<.018)$ and masters supervised $(p<.025)$ are the only other significant predictors of doctoral supervision.

On the basis of these results, it is concluded that academic staff may need to be supported and empowered to be more confident about being able to apply statistical methods; this might be one mechanism whereby doctoral supervisions can be increased.

Table 1. Descriptive statistics for job satisfaction and the self-efficacy measures

\begin{tabular}{|l|c|c|c|c|}
\hline \multicolumn{1}{|c|}{ Variable } & Mean & Standard Deviation & Skewness & Kurtosis \\
\hline Job Satisfaction & 15.07 & 4.025 & .162 & .854 \\
\hline Satisfaction with teaching & 4.25 & 1.58 & -.128 & -.561 \\
\hline Research self-efficacy & 425.25 & 106.36 & -.496 & .227 \\
\hline International journal publication self-efficacy & 71.87 & 25.16 & -.587 & -.408 \\
\hline DOHET journal publication self-efficacy & 74.29 & 25.18 & -.847 & .186 \\
\hline Conference proceedings publication self-efficacy & 76.39 & 23.81 & -1.09 & .920 \\
\hline Conference presentation self-efficacy & 81.5 & 21.35 & -1.29 & 1.444 \\
\hline Statistical analysis self-efficacy & 49.88 & 33.4 & -.087 & -1.217 \\
\hline Qualitative analysis self-efficacy & 71.33 & 27.47 & -1.03 & .417 \\
\hline Postgraduate teaching self-efficacy & 84.94 & 20.54 & -1.464 & 1.327 \\
\hline Age & 40.67 & 10.56 & .420 & -.337 \\
\hline Gender (male=1) & .47 & - & - & - \\
\hline Total years of work experience & 14.6 & 10.69 & .769 & -.086 \\
\hline Years of experience as a researcher & 10.2 & 8.84 & 1.598 & 2.789 \\
\hline Years working for the institution & 6.39 & 6.74 & 2.443 & 8.402 \\
\hline Masters supervised & 6.19 & 9.554 & 2.561 & 8.106 \\
\hline Doctorates supervised & .95 & 2.731 & 5.107 & 35.605 \\
\hline
\end{tabular}

*Indicates binary variable: is expressed as a percentage, and not as a mean. 
Table 2: Hierarchical Linear Regression Results

\begin{tabular}{|c|c|c|c|c|c|c|}
\hline $\begin{array}{c}\text { Dependent } \\
\text { variable }\end{array}$ & \begin{tabular}{|c|} 
Model 1 \\
Doctoral Supervisions
\end{tabular} & \begin{tabular}{|c|} 
Model 2 \\
Doctoral Supervisions
\end{tabular} & \begin{tabular}{|c|} 
Model 3 \\
Doctoral Supervisions
\end{tabular} & \begin{tabular}{|c|} 
Model 4 \\
Doctoral Supervisions \\
\end{tabular} & \begin{tabular}{|c|} 
Model 5 \\
Masters Supervisions
\end{tabular} & \begin{tabular}{|c|} 
Model 6 \\
Masters Supervisions \\
\end{tabular} \\
\hline Constant & -.975 & $-2.160^{*}$ & $-1.499^{*}$ & $-2.083^{\star}$ & 3.943 & -.459 \\
\hline Job satisfaction & $.02(.03) /-.055(\mathrm{l}) ; .092(\mathrm{u})$ & $\begin{array}{l}.002(.003) /- \\
.082(\mathrm{l}): .081(\mathrm{u})\end{array}$ & $\begin{array}{l}.042(.062) /- \\
.022(1): .110(h)\end{array}$ & $\begin{array}{l}.032(.047) /- \\
.029(\mathrm{l}): 089(\mathrm{~h})\end{array}$ & $\begin{array}{l}-.163(-.069) /- \\
.420(l): .112(h)\end{array}$ & $\begin{array}{l}-.230(-.097) /- \\
.504(\mathrm{l}): .009(\mathrm{u})\end{array}$ \\
\hline \begin{tabular}{|l|} 
Years as a \\
researcher
\end{tabular} & $\begin{array}{c}.102(.329)^{*} / .058(\mathrm{l}) ; .148 \\
(\mathrm{u})\end{array}$ & $\begin{array}{c}.09(.291)^{\star *} / .033(1) ; .135( \\
\mathrm{u})\end{array}$ & $\begin{array}{c}.045(.147) /- \\
.041(\mathrm{~h}) ; .111(\mathrm{~h}) \\
\end{array}$ & $\begin{array}{l}.041(.133) /- \\
.035(\mathrm{l}) ; .101(\mathrm{~h}) \\
\end{array}$ & $\begin{array}{c}.420(.388)^{\star} /(.263(\mathrm{l}) ; .594 \\
(\mathrm{h})\end{array}$ & $\begin{array}{c}.375(.347)^{* *} / .216(l) ; 546( \\
u)\end{array}$ \\
\hline People reporting & $.055(.130) /-.02(\mathrm{l}) ; .191(\mathrm{u})$ & $.052(.124) /-.02(\mathrm{l}) ; .203(\mathrm{u})$ & $\begin{array}{l}.002(.005) /- \\
.047(\mathrm{l}) ; .082(\mathrm{~h})\end{array}$ & $\begin{array}{l}.002(.005) / .- \\
.057(\mathrm{l}) / .105(\mathrm{~h})\end{array}$ & $\begin{array}{c}.385(.260) * / .03(l) ; .698(h \\
)\end{array}$ & $.374(.253) / .01()) ; .749(u)$ \\
\hline Gender & $\begin{array}{c}.927(.170) * / .318(\mathrm{l}) ; 1.659 \\
(\mathrm{u})\end{array}$ & $\begin{array}{c}.773(.142) * / .233(\mathrm{l}) ; 1.438 \\
(\mathrm{u})\end{array}$ & $\begin{array}{c}1.087(.199)^{*} / .515(\mathrm{l}) ; 1.606 \\
(\mathrm{~h})\end{array}$ & $\begin{array}{c}1.003(.183)^{\star} / .439(\mathrm{l}) ; 1.592 \\
(\mathrm{~h})\end{array}$ & $\begin{array}{l}-1.262(-.066) /- \\
3.628(l) ; .994(h)\end{array}$ & $\begin{array}{l}-1.832(-.096) /- \\
4.323(() ; 632(u)\end{array}$ \\
\hline \begin{tabular}{|l}
$\begin{array}{l}\text { Research self- } \\
\text { efficacy }\end{array}$ \\
\end{tabular} & & $\begin{array}{c}.004(.152) * /(001(1) ; .007( \\
\mathrm{u})\end{array}$ & & $.002(.077) / .000(\mathrm{l}) ; .004(\mathrm{~h})$ & & \begin{tabular}{|c|}
$.014(.161)^{* *} .005(\mathrm{l}) ; .025$ \\
$(\mathrm{~h})$
\end{tabular} \\
\hline \begin{tabular}{|l} 
Masters \\
supervisions
\end{tabular} & & & $\begin{array}{c}.136(.476) * / .051(l) ; 259(\mathrm{~h} \\
)\end{array}$ & $\begin{array}{c}.132(.461) * / .049(l) ; 255(\mathrm{~h} \\
)\end{array}$ & & \\
\hline \begin{tabular}{|l|} 
Durbin-Watson \\
\end{tabular} & 2.044 & 2.029 & 2.081 & 2.075 & & \\
\hline R squared & .188 & $\begin{array}{c}.207(+.019 \text { over Model } \\
1)\end{array}$ & .351 (.163 over Model 1$)$ & $.356(.168$ over Model 1$)$ & 281 & .303 \\
\hline Adjusted R squared & .173 & .189 & .336 & .338 & .268 & 287 \\
\hline $\begin{array}{l}\text { Standard error of } \\
\text { the estimate }\end{array}$ & 2.484 & 2.459 & 2.230 & 2.226 & 8.176 & 8.067 \\
\hline F-value & $12.697^{* \star \star}$ & $11.454^{\star \star \star}$ & $23.567^{* * *}$ & $19.974^{\star \star \star}$ & $21.368^{\star \star \star}$ & $18.955^{* * *}$ \\
\hline
\end{tabular}

Notes: ${ }^{\star} p<.05 ;{ }^{* \star} p<.01 ;{ }^{\star \star \star} p<.001$. Coefficient is before slash/standardised coefficient is after slash. Bootstrap results are based on 1000 bootstrap samples.

\subsection{Hypothesis $b$ : there is a significant association between research-related self-efficacy and the number of mastes studnets an academic has supervised.}

According to the Spearman tests of association, masters supervisions are associated with total research self-efficacy $(.241 ; \mathrm{p}<.0001 ; \mathrm{Cl}$ low=.118; $\mathrm{Cl}$ high=.369), ISI/IBSS journal article publication self-efficacy $(.250 ; \mathrm{p}<.0001 ; \mathrm{Cl}$ low $=.121 ;$ $\mathrm{Cl}$ high=.380), DOHET journal article publication self-efficacy $(.293 ; \mathrm{p}<.0001 ; \mathrm{Cl}$ low=.168; Cl high=.411), conference proceedings publication self-efficacy $(.216 ; \mathrm{p}<.001 ; \mathrm{Cl}$ low=.09; $\mathrm{Cl}$ high=.334), conference presentation self-efficacy (.181;p<.007; Cl low=.054; Cl high=.315) and qualitative analysis self-efficacy (.186; $p<.005 ; \mathrm{Cl}$ low=.059; $\mathrm{Cl}$ high=.311). Masters supervisions, however, are not significantly associated with statistical analysis $(-.009 ; \mathrm{p}<.896 ; \mathrm{Cl}$ low=-.144; $\mathrm{Cl}$ high=.125), unlike doctoral supervisions.

When the influence of years of experience as a researcher was controlled for using Pearson partial correlation analysis, masters supervision is positively and significantly associated with total research self-efficacy $(.141 ; \mathrm{p}<.035 ; \mathrm{Cl}$ low=.036; $\mathrm{Cl}$ high=.240) and conference proceedings publication self-efficacy $(.152 ; \mathrm{p}<.023 ; \mathrm{Cl}$ low=.06; $\mathrm{Cl}$ high=.235).

However, with the influence of years of experience controlled for, the associations between masters degree supervision and the following forms of self-efficacy are not significant at the five percent level of significance: ISI/IBSS journal publication self-efficacy $(.107 ; \mathrm{p}<.111 ; \mathrm{Cl}$ low=.002; Cl high=.201); DOHET journal publication self-efficacy (.173;p<.01; Cl low=.065; Cl high=.265); conference presentation self-efficacy $(.11 ; p<.10 ; \mathrm{Cl}$ low=.022; $\mathrm{Cl}$ high=.183); statistical analysis self-efficacy $(.008 ; \mathrm{p}<.909 ; \mathrm{Cl}$ low=-.114; $\mathrm{Cl}$ high=.141) and qualitative analysis self-efficacy $(.06 ; p<.375 ; \mathrm{Cl}$ low=-.047; Cl high=.157).

Unlike the case of doctoral supervision, according to the bivariate tests, masters supervisions are negatively associated with general job satisfaction $(-.135 ; p<.044)$. Masters supervisions are also positively associated with selfefficacy related to postgraduate teaching $(.372 ;$ p <.0001).

The negative association between masters degree supervisions and general job satisfaction is unexpected. Further research is suggested in order to investigate this relationship. It is acknowledged that some causal mechanism might underlie this relationship; that masters supervision might be acting as a proxy variable to pick up some underlying effect that is outside the direct scope of this investigation.

According to the bivariate tests, masters degree supervisions are also positively associated with age $(.415 ; p<.0001)$, other countries lived in for a period of over a year $(.259, p<.0001)$, total years of work experience $(.456 ; p<.0001)$, years as a researcher $(.588 ; p<.0001)$, years working for the institution $(.507 ; p<.0001)$, membership of professional associations $(.288 ; p<.0001)$, years of formal education $(.162 ; p<.015)$ and the number of people reporting to an individual $(.321 ; p<.0001)$. The human capital variables relating to experience conform to the predictions of Becker's (1975) human capital theory. The strongest of these associations was years as a researcher, which was used in the multivariate testing. 
According to the multivariate results (Table 4), total research self-efficacy is found to be a significant predictor of masters supervisions over and above the influence of the covariates. The model including research self-efficacy explains $28.7 \%$ of the variance in masters supervisions. When doctoral supervision is added to the model as a predictor of masters degree supervision, the $\mathrm{R}$ squared value for the model is .433, indicating that under half of the variance in masters degree supervision is explained by the variables in the model. In this model, the doctoral supervision variable has the highest standardised coefficient $(\beta=.405)$, almost double the value of the next highest, years of experience as a researcher $(\beta=.228)$. As in the case of doctoral supervision, when a measure of the corresponding form of postgraduate supervision is added to the equation, total research self-efficacy reduces in significance; in this case to $p<.078$ $(\mathrm{Cl}(\mathrm{l})=.001 ; \mathrm{Cl}(\mathrm{h})=.018)$. These findings suggest that one form of postgraduate supervision (doctoral or masters supervision) dominates in its association with the other; over and above the associations of other factors.

The implication of this is that self-efficacy may contribute significantly to postgraduate supervision in the absence of previous experience of one form of postgraduate supervision or the other. These findings support the predictions of Bandura (2006) for individuals that need to develop their confidence and gain initial experience in postgraduate supervision. However, these findings suggest a boundary condition for the operation of Bandura's theory in this context; once indivdiuals have sufficient experience of one form of postgraduate supervision or the other, self-efficacy seems to no longer be significantly associated with numbers of successful postgraduate supervisions, of one form or the other.

According to these results, having more people reporting to an individual and years as a researcher are also significant predictors of masters supervisions. Interestingly, gender is not a significant predictor of masters degree supervisions, unlike in the case of doctoral supervisions.

\section{Concluding Remarks}

On the basis of these results, if individuals that successfully supervise more doctoral students are indeed significantly less satisfied with teaching and more satisfied with research, then it is recommended that workload models be responsive to the intrinsic satisfaction profiles of more doctoral supervision-productive individuals. The negative job satisfaction related to masters degree supervisions is difficult to interpret.

These findings support Bandura's (2006) predictions; that self-efficacy is associated with higher levels of both doctoral and masters supervisions, but only up to the point at which experience of postgraduate supervision (of one form or the other) is taken into account.

According to their research into self-efficacy, Strajkovic and Luthans (1998:255) suggest that in order to improve performance on tasks, individuals should receive training "in developing effective behavioural and cognitive strategies for coping with complex tasks", and be provided with the necessary incentives. Programmes that focus on increasing the self-efficacy of academics to supervise postgraduate students should be tailored to those that have yet to develop experience of supervision. A specific focus on building confidence in qualitative research skills is recommended initially, for academics yet to supervise masters students, and then for statistical skills in order to empower doctoral supervision. Building the confidence of academics in both of these types of methods might improve postgraduate supervision.

Programmes to enhance self-efficacy should be related to 'learning by doing' (Bandura, 2006); mentorship programmes should be built around practical research collaborations as well as collaborative supervisions.

Certain solutions to the shortage of doctoral supervisors have been mooted; such as bringing senior academics back into universities; from science councils and industry, but also by bringing individuals out of retirement (ASAf, 2010). Similarly, targeted recruitment can bring in recruits from other countries (ASAF, 2010). However, efforts aimed at increasing the capacity of supervisors should perhaps be a primary focus of this process. It is argued that the findings of this study support Bandura's (2006) argument; that a primary way to empower supervisors to be more productive is through measures designed to increase their self-efficacy.

\section{References}

Albertyn, R. M., Kapp, C. A., \& Bitzer, E. M. (2008). Profiling exiting postgraduate students' performance and experiences. South African Journal of Higher Education, 22(4), 749-772.

Arvey, R. D., Bouchard, T. J., Segal, N. L., \& Abraham, L. M. (1989). Job Satisfaction: Environmental and Genetic Components. Journal of Applied Psychology, 74(2): 187-192.

Aspland, T., Edwards, H., O'Leary, J., \& Ryan, Y. (1999). Tracking New Directions in the Evaluation of Postgraduate Supervision. Innovative Higher Education, 24(2), 127-147.

ASSAf (2010). The PHD Study. An Evidence-based Study on how to meet the demands for High-level Skills in an Emerging Economy. 
Academy of Science of South Africa. <http://www.assaf.co.za/wp-content/uploads/2010/11/40696-Boldesign-PHD-small.pdf> (accessed June 13, 2013).

Bandura, A. (1977). Self-Efficacy: toward a unifying theory of behavioural change. Psychological review, 84(2), 191-215.

Bandura, A. (1982). Self-efficacy mechanism in human agency. American Psychologist, 37, 122-147.

Bandura, A. (2006). Guide for constructing Self-Efficacy scales. In F. Pajares \& T. Urdan (Eds.). Self-Efficacy Beliefs of Adolescents, (Volume 5, pp.307-337). Greenwich: Information Age Publishing.

Becker, G. S. (1964). Human Capital. University of Chicago Press, Chicago.

Bernadowski, C., Perry, R., \& Del Greco, R. (2013). Improving Preservice Teachers' Self-Efficacy through Service Learning: Lessons Learned. International Journal of Instruction, 6(2), 67-86.

Bitzer, E. M. (2011). Knowledge with wisdom is postgraduate studies and supervision: Epistemological and institutional concerns and challenges. South African Journal of Higher Education, 25(5), 855-874.

Briley, J. (2012). The relationships among Mathematical Teaching Efficacy, Mathematics Self-Efficacy, and Mathematical Beliefs for Elementary Pre-Service Teachers. Issues in Undergraduate Mathematics Preparation of School Teachers, 5. <http://www.k12prep.math.ttu.edu/journal/attributes/briley01/article.pdf> (accessed October 16, 2013).

Brown, C., \& Czerniewicz, L. (2010). Debunking the 'digital native': beyond digital apartheid, towards digital democracy. Journal of Computer Assisted Learning, 26, 357-369.

Calik, T., Sezgin, F., Kavgaci, H., \& Kilinc, A. C. (2012). Examination of Relationships between Instructional Leadership of School Principles and Self-Efficacy of Teachers and Collective Teacher Efficacy. Educational Sciences: Theory and Practice, 12(4), 2498-2504.

Callaghan, C. W. (2012). Informal Development in Relatively Involuntary Employment: Continuance Satisfaction and Informal Trading Effects in the Southern African Context. Journal of Economics (Delhi), 3(2), 83-93.

Fraser, R., \& Mathews, A. (1999). An evaluation of the desirable characteristics of a supervisor. Australian Universities Review, 42(1), 57.

Ghasemizad, A., Khajehei, H., \& Mohamadkhani, K. (2013). School level environment and elementary teachers' self efficacy: structural equation model. Australian Journal of Basic and Applied Sciences, 7(8), 589-594.

Giddens, A. (1984). The constitution of society: outline of the theory of structuration. Berkley and Los Angeles: University of California Press.

Hackman, J. R., \& Oldham, G. R. (1976). Motivation through the Design of Work: Test of a Theory. Organizational Behaviour and Human Performance, 16, 250-279.

Herzberg, F. (1968). One more time: How do you motivate employees? Harvard Business Review, January-February, 53-62.

Judge, T. A., Thoresen, C. J., Bono, J. E., \& Patton, G. K. (2001). The Job Satisfaction-Job Performance Relationship: A Qualitative and Quantitative Review. Psychological Bulletin, 127(3), 376-407.

Locke, E. A. (1969). What is job satisfaction? Organizational behaviour and human performance, 4(4), 309-336.

Locke, T., Whitehead, D., \& Dix, S. (2013). The impact of 'writing project' professional development on teachers' self-efficacy as writers and teachers of writing. English in Australia, 48(2), 55-69.

Mouton, J. (2007). Post-graduate studies in South Africa: Myths, misconceptions and challenges. South African Journal of Higher Education, 21(8), 1078-1090.

Organ, D. W. (1988). Organizational citizenship behavior: The good soldier syndrome. Lexington Books, Lexington, MA.

Singh, S. (2011). An intervention to assist students with writing their dissertations and theses. South African Journal of higher education, 25(5):1020-1030.

Stajkovic, A. D., \& Luthans, F. (1998). Self-efficacy and work-related performance: A meta-analysis. Psychological Bulletin, 124(2), 240261.

Waghid, Y. (2011). Initiating Debate. On Cavellian scepticism and postgraduate student supervision. South African Journal of Higher Education, 25(3), 393-396.

Winberg, C. (2009). Engineers are from Mars and educators are from Venus: Research supervision in engineering and educational collaboration. South African Journal of Higher Education, 23(1), 205-217. 